\title{
RESEARCH OF TRAFFIC MANAGEMENT IN FTTX OPTICAL COMMUNICATION SYSTEMS
}

\author{
V. Bobrovs, J. Jelinskis, G. Ivanovs, G. Lauks \\ Institute of Telecommunications, Riga Technical University, \\ 12 Āzenes Str., Rīga, LV-1048, LATVIA
}

The paper presents an overview of widely accepted passive optical networks (PONs), and provides the results of comparative OPTSIM simulation for PON technological facilities involving optical layers, with the aim to reveal fiber-to-the-x (FTTx) technologic solutions. Traffic load is simulated over a PON optical layer using the OPNET Modeler to determine potential advantages and drawbacks of the proposed FTTx solution with PON elements in the access networks. The authors show that the optimal transmission speed for PON FTTx would lie in the range 1.25$5.0 \mathrm{Gbit} / \mathrm{s}$ with a standard PON architecture, which could be raised to $10 \mathrm{Gbit} / \mathrm{s}$, however in this case we have to change the end user's equipment. In standards that specify the PON's functionality two distances: $10 \mathrm{~km}$ and $20 \mathrm{~km}$ are indicated. Our simulation shows that, after upgrading the receiver electrical filter, $10 \mathrm{Gbit} / \mathrm{s}$ transmissions over $40 \mathrm{~km}$ could be reached. engineering.

Key words: passive optical networks (PONs), fiber-to-the-x (FTTx), traffic

\section{INTRODUCTION}

Owing to the rapidly growing capacity requirements for long distance transmission, fiber optic telecommunications are advancing into high data rate enabled services. There is little doubt that, after 25 years of being the future technology for access networks, the fiber-to-the-home (FTTH) infrastructure, mainly in the form of passive optical network (PON) systems, is now being deployed actively in Asia and USA, and is beginning to pick up pace also in Europe $[1,2]$. In the light of the growing PON system market, extensive research has been conducted over the last years in the areas of multiple access (MA) techniques, dynamic bandwidth allocation (DBA) mechanisms, quality of service (QoS) support, security mechanism as well as next generation system upgrades.

The convergence of voice, data, and video services as well as the insatiable appetite of customers for bandwidth places a burden on the access network (AN) to deliver high data rates in a cost-effective manner. Passive optical networks and fiber-to-the-premises (FTTP) technologies hold the highest promise for ANs. These point-to-multipoint fiber-based architectures are capable of delivering high traffic rates through single or multiple channels, while amortizing the cost of the infrastructure over a large number of consumers.

At the end of 2007, there were nearly 29 millions of subscribers connected with fiber-to-the-x (FTTx) infrastructure worldwide [2] (see Fig. 1). Most of the subscribers are receiving data transmission service via fiber-to-the-home (FTTH) 
or fiber-to-the-building (FTTB). The FTTH Council is promoting the deployment of FTTH worldwide by tracking the increasing subscriber numbers on FTTH and its increasing market share of all broadband [3]. By the FTTH Council data provided, in January 2008 eleven countries or economies had a greater than 1 percent FTTH penetration. In the six months since then, the number of countries having a greater than 1 percent penetration rate increased to 14 (Fig. 2, [1]).

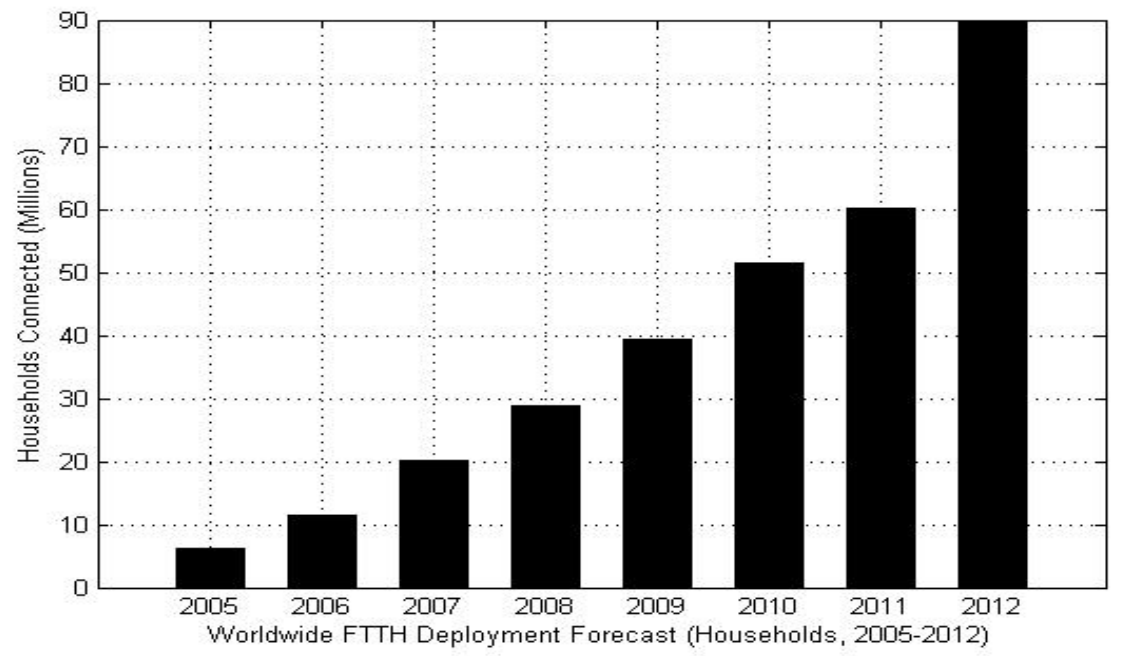

Fig. 1. Worldwide FTTH Deployment Forecast (Housholds up to 2012) [2].

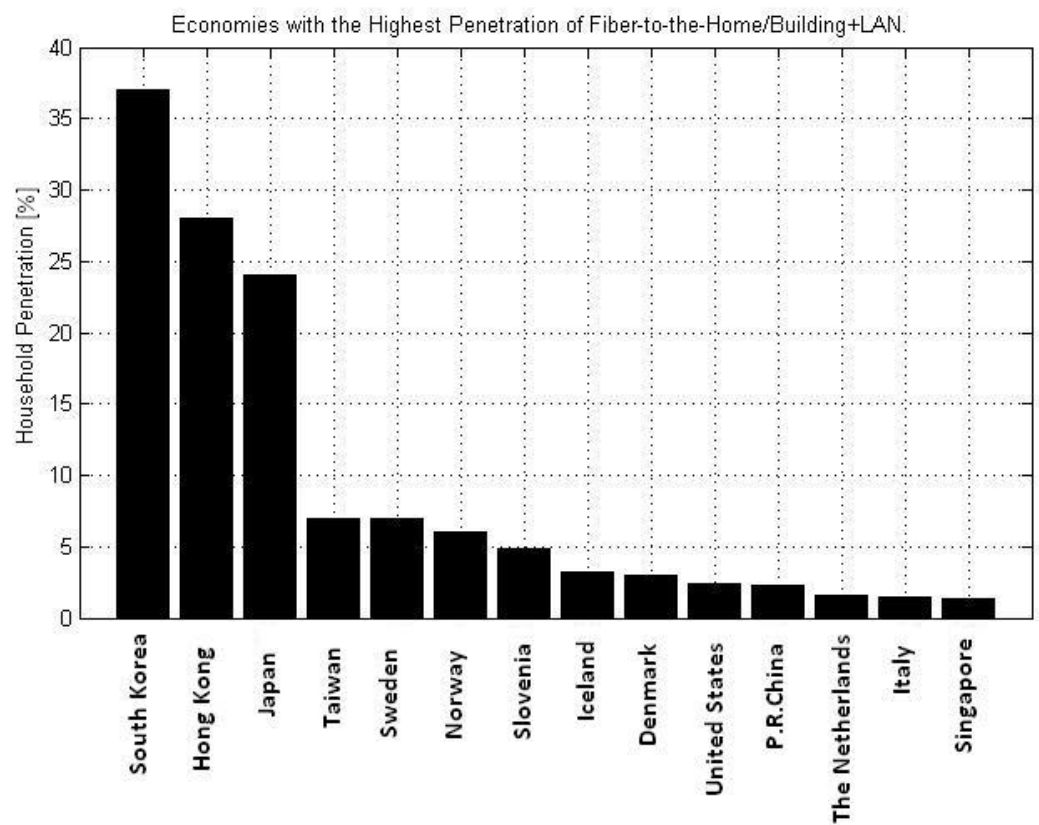

Fig. 2. Economies with greater than 1\% household penetration. Mid-Year 2008 ranking [1].

The fastest growing regions for PON sales are forecasted to be Western Europe and North America. Telecommunication companies generally agree that 
fiber all the way to the home or premises is the ultimate broadband. It is known that aggregated traffic in the Internet may experience a high degree of variability. Over the past decade many studies of traffic patterns revealed that traffic aggregates may also experience changes in their statistical characteristics often manifesting non-stationary behavior. Self-similarity, long-range dependence, and being non-stationary are three major underlying reasons for a traffic pattern to be susceptible to high variability.

With the tremendous growth of broadband IP services, the impact of the bandwidth bottleneck in the access networks becomes more prominent, and largely restricts the network carriers (NCs) to provide satisfactory services for subscribers. Thus, a new access network with sufficient bandwidth resources and efficient resource management should be designed. Excellent solution for these problems would be the FTTH access networks based on different technologies.

In this paper we have provided an overview of current PON-based FTTH solutions, and an example scenario for evolution towards the $10 \mathrm{Gbit} / \mathrm{s}$ bit rate. In the literature, many research works are found focusing on PON, but only few of them deal with migration strategies that enable smooth and logical transition to a $10 \mathrm{Gbit} / \mathrm{s}$ PON.

\section{ACCESS ARCHITECTURES}

There are three basic types of architectures being used to provide FTTH. The most common of them is the PON technology, which allows multiple homes to share a passive fiber network. In this type of network, the plant between the customer premises and the head-end at the central office consists entirely of passive components - no electronics are needed in this case.

Other architectures being used are the home-run fiber (or point-to-point fiber), in which subscribers have a dedicated fiber strand, with active or powered nodes employed to manage signal distribution, and hybrid PONs, which are a combination of the home-run and the PON architectures. Although the FTTH technology is still in its infancy, the deployment of FTTH is growing significantly. Also, the equipment costs for FTTH have considerably decreased [3].

In addition to FTTH technologies, some network carriers are constructing fiber-to- the-curb (FTTC) facilities that do not run all the way to the home but run to a pedestal located within 100-150 meters of the subscriber premises. Copper lines are then used for connection between the pedestal and the network interface device at a customer's premises. Because of the limited use of copper, FTTC technologies permit carriers to provide high-speed data in addition to high definition video services.

Design and deployment activities for access networks are on the rise in order to support the increasing demands and delivery of new multimedia services to the customer premises, such as interactive video, voice, and high-speed Internet.

From the great number of FTTH technologies mentioned above, for our investigation we have chosen the most popular one, which is based on the concept of using a passive fiber distribution network (known as PON). The FTTH employing PON access architecture is the accepted choice of the delivery channel for triple-play services (voice, video and data) from service providers to the home and business users worldwide [4]. 


\section{OPTICAL LAYER SIMULATION FOR FTTX OPTICAL COMMUNICATION SYSTEM WITH TDM-PON SOLUTION}

Our research is based on the evaluation of the bit error rate (BER) using powerful techniques incorporated in the RSOFT OptSim 5.0 simulation software. In the present work, we show the spectrum and eye diagrams for various simulation setups, since they comprise the fast approach of an approximate evaluation of a system's performance; respectively, an eye has to be open wide enough, and spectrum diagrams should be regular, without negative multi-peak structure for a good system performance. An eye diagram shows the patterns of the electrical signal after detection. The eye height is an indicator of noise, whereas the signal width at the center of an eye diagram represents a measure of timing jitter [5].

The accepted method of calculation is based on solving a complex set of differential equations, taking into account optical and electrical noise as well as linear and nonlinear effects. We have used a model where signals are propagating as time domain samples over a selectable bandwidth (in our case, a bandwidth that contains all channels). The Time Domain Split Step (TDSS) method was employed to simulate linear and nonlinear behavior for both optical and electrical components. The split step method is now used in all commercial simulation tools to perform the integration of a fiber propagation equation that can be written as

$$
\frac{\partial A(t, z)}{\partial z}=\{L+N\} A(t, z) .
$$

Here $A(t, z)$ is the optical field;

$L \quad$ is the linear operator that stands for dispersion and other linear effects;

$N \quad$ is the operator that is responsible for all nonlinear effects.

The idea was to calculate the equation over small spans of fiber $\Delta z$ by including either a linear or a nonlinear operator. For instance, on the first span $\Delta z$ only linear effects are considered, on the second - only nonlinear, on the third - again only linear ones, and so on. Two ways of calculation are possible: frequency domain split step (FDSS) method and the above-mentioned time domain split step (TDSS) method. These methods differ in how linear operator L is calculated: FDSS does it in a frequency domain, whereas TDSS - in the time domain, by calculating the convolution product in sampled time. The first method is easy to fulfill, but it may produce severe errors during computation. In our simulation we have employed the second method, TDSS, which, despite its complexity, ensures an effective and time-efficient solution [5].

In a passive optical network, the active optoelectronics are situated on its either ends. An optical line termination (OLT) device is installed in the central office (CO), and an optical network termination (ONT) device - on the other end, inside or near each home or business site. The fiber distribution is done using a tree-and-branch architecture. A single fiber connected to the OLT can be split up to 32 times and connected to multiple ONTs. The current simulation example shown in Fig. 3 models a FTTH design with 32 subscribers and 20 or $40 \mathrm{~km}$ reach, and the idea is to compare the system performance using various fiber lengths and bit rates. The central office is connected through a $15 \mathrm{~km}$ or $35 \mathrm{~km}$ standard single mode fiber to the first remote node with a 1:4 splitter. Each of the four outputs goes through 


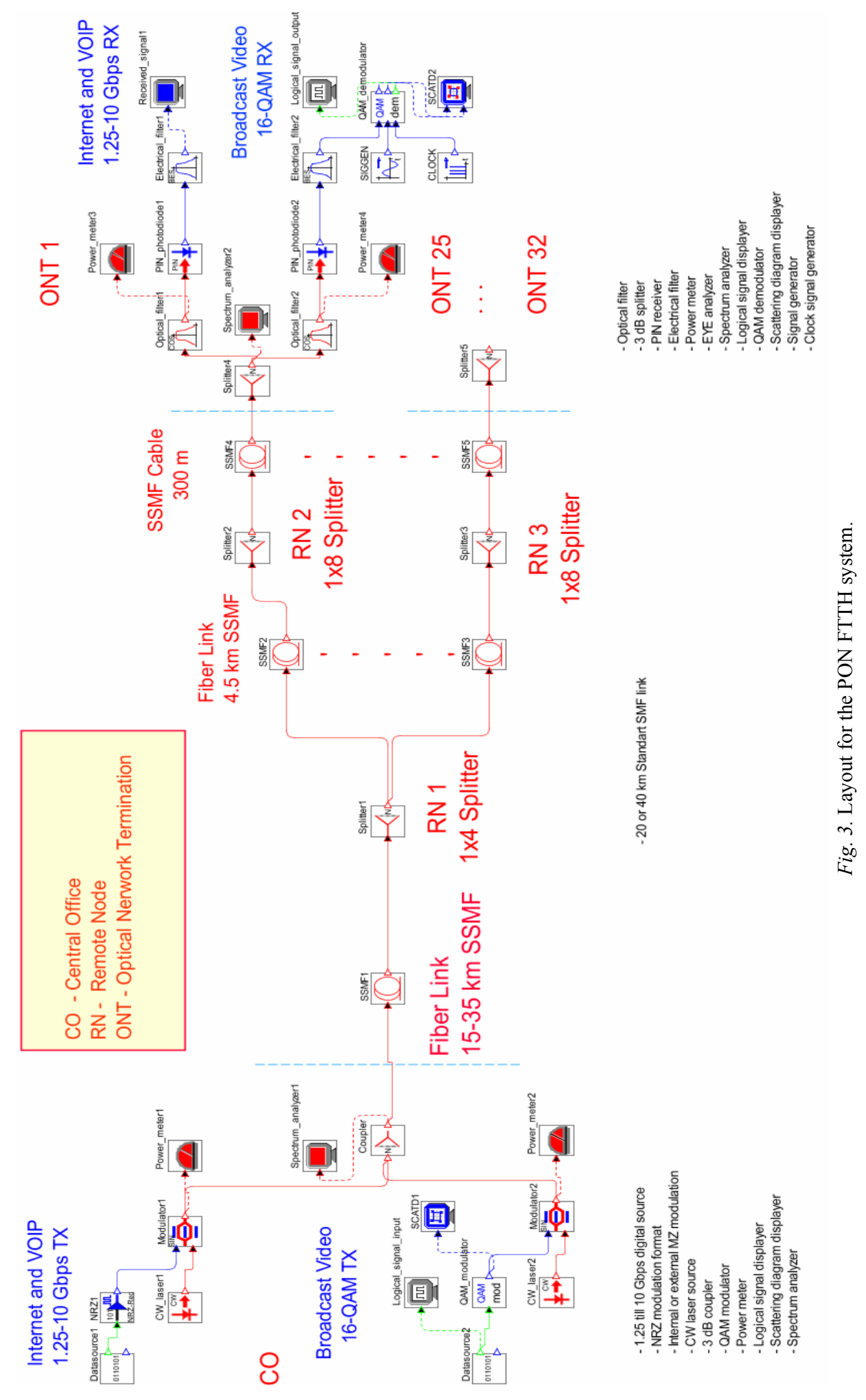


another $4.5 \mathrm{~km}$ fiber and then enters the Remote Node with a 1:8 splitter. Outputs from the 1:8 splitters are connected to eight end-users at the ONT through drop-off cables of a length varying from 100 to 300 meters. Each optical channel is filtered, converted to an electrical one and then electrically filtered [6]. To evaluate the system performance several measurements were taken. We were interested in observing the optical spectrum at the beginning and at the end of an optical link, as well as in the quality of eye and scattering diagrams and bit error rates (BERs) [7].

\section{TRAFFIC MANAGEMENT SIMULATION IN FTTX OPTICAL COMMUNICATION SYSTEM WITH TDM-PON SOLUTION.}

In this research the Opnet Modeler 14.0 was used for PON logical topology simulation as well for traffic data synthesis. The Opnet Modeler is a powerful tool, which is employed for network performance analysis with many different topological solutions and event scenarios.

Every simulation starts with construction of a virtual topological network testbed, which is then utilized with synthesized traffic going through the links and nodes. For the PON simulation the gigabit Ethernet PON (GEPON) was selected, which is an IEEE/EFM standard for using Ethernet for packet data and the most popular solution worldwide nowadays [8].

The topological solution is based on a standard data switch which is used for linking services to the PON fiber trunk, which is represented as Ethernet link with 1 Gbps data throughput. This choice was made based on the standard in most modern end-user equipment data interfaces. The passive optical splitter is represented with a plain data hub, which makes it easy to split Ethernet packets to all the 32 end-user equipment workstations. Every workstation is connected with the same $1 \mathrm{Gbps}$ Ethernet link which is used to link Switch and Hub.

In this investigation, when dealing with traffic management we proposed the most modest simulation scenario, when the link data throughput is limited to $1 \mathrm{Gbps}$. The network user profile is composed taking into account the most popular applications and services used through the network. Table 1.

The user profile configuration data with predefined applications are given in

Table 1

PON user profile configuration

\begin{tabular}{|l|l|l|l|l|}
\hline Start time [s] & Duration & Operation Mode & $\begin{array}{c}\text { Inter-repetition } \\
\text { time [s] }\end{array}$ & \multicolumn{1}{|c|}{$\begin{array}{c}\text { Supported } \\
\text { applications }\end{array}$} \\
\hline constant (1) & End of simulation & Simultaneous & exponential (20) & $\begin{array}{l}\text { File Transfer } \\
\text { (Heavy) }\end{array}$ \\
\hline constant (1) & End of simulation & Simultaneous & exponential (30) & $\begin{array}{l}\text { Video over IP } \\
\text { (Heavy) }\end{array}$ \\
\hline constant (1) & End of simulation & Simultaneous & exponential (20) & $\begin{array}{l}\text { Peer-to-peer } \\
\text { (Heavy) }\end{array}$ \\
\hline constant (1) & End of simulation & Simultaneous & exponential (20) & $\begin{array}{l}\text { Web Browsing } \\
\text { (Heavy HTTP1.1) }\end{array}$ \\
\hline constant (1) & End of simulation & Simultaneous & exponential (30) & Email (Heavy) \\
\hline constant (1) & End of simulation & Simultaneous & exponential (30) & $\begin{array}{l}\text { Voice over IP Call } \\
\text { (PCM Quality) }\end{array}$ \\
\hline
\end{tabular}


We should admit that the user profile configuration data for traffic characteristics given in Table 1 are to a great extent subjectively constructed due to the woolly outlines of the current user behavior portrait in the context of traffic consumption and generation by modern end-user and server-side applications. We therefore base our assumption on the vision of modern network architecture where comparatively powerless end-user equipment in tandem with broadband internet connection makes it easy to put practically every application on the market in the on-line mode. Innumerable modern WEB2.0 services, online audio, video and interactive IPTV (Video on Demand, Time Shifted TV, Network Personal Video Recorder, etc.) as well as photo hosting make it senseless to keep big amounts of information on the hard disk, and encourage computer engineers to organize the storage on remote servers and the on-line access.

In the opinion of Gartner [9], who is the largest technology adviser to corporations, "the cloud computing is underway and will make the most visible impact on the IT industry in the next few years and be as influential as e-business".

The peer-to-peer computation, which uses decentralized manner connections, is employing huge amounts of bandwidths nowadays. File exchange is a massive phenomenon, and such applications as E-Mule, Bit-Torrent and others make it possible to organize piece-by-piece huge file transfer from multiple users worldwide.

All the advances mentioned above have the impact of dense inter-repetition times in the data throughput profile configuration, which employs the file transfer, video over IP, peer-to-peer, web browsing, e-mail access and voice over IP applications in a heavy manner (for the corresponding PON topology see Fig. 4).



Fig. 4. Passive optical network topology. 


\section{RESULTS AND DISCUSSION}

In our PON simulation the link utilization (data throughput) and the queuing delay were tracked. The data throughput whose synthesis is based on a subjectively assumed traffic profile configuration (see Fig. 4) shows that a $1 \mathrm{Gbps}$ link is mostly satisfactory for 32 end-users at the end of one optical trunk. This assumption results in the stabilization of average link utilization at approx. $12 \%$ of the link capacity (see Figs. 5 and 6). The most serious problem is the high rate burstiness of traffic throughput in the course of time (see Figs. 5 and 7).

The end-to-end delay in a PON system (see Fig. 8), counting from the switch line connection, is rising non-monotonically (which means that the queuing buffers are not overloaded) and stays mostly in the feasible constraints of $0.00001 \mathrm{~s}$. Indeed, the burstiness of traffic makes it to rise over 50 times to the $0.005 \mathrm{~s}$ in short periods of time, when the link utilization rises $100 \%$. The current time division multiplexing PONs (TDM-PONs) are bandwidth-limited, so when the user demand outgrows the existing network capacity upgrading the bandwidth of existing TDMPON will be a challenge, as its MAC protocol is highly complicated.

Also, the TDM-PON have only one wavelength for downstream (two wavelengths in the case of video overlay) and one for upstream data, thus limiting the average bandwidth per user to few tens of Mbps [2]. In this way the available bandwidth of a single fiber is mostly wasted; moreover, the tree topology of current TDM-PON lacks the features of protection and restoration.



Fig. 5. Switch-Hub link throughput + trendline.

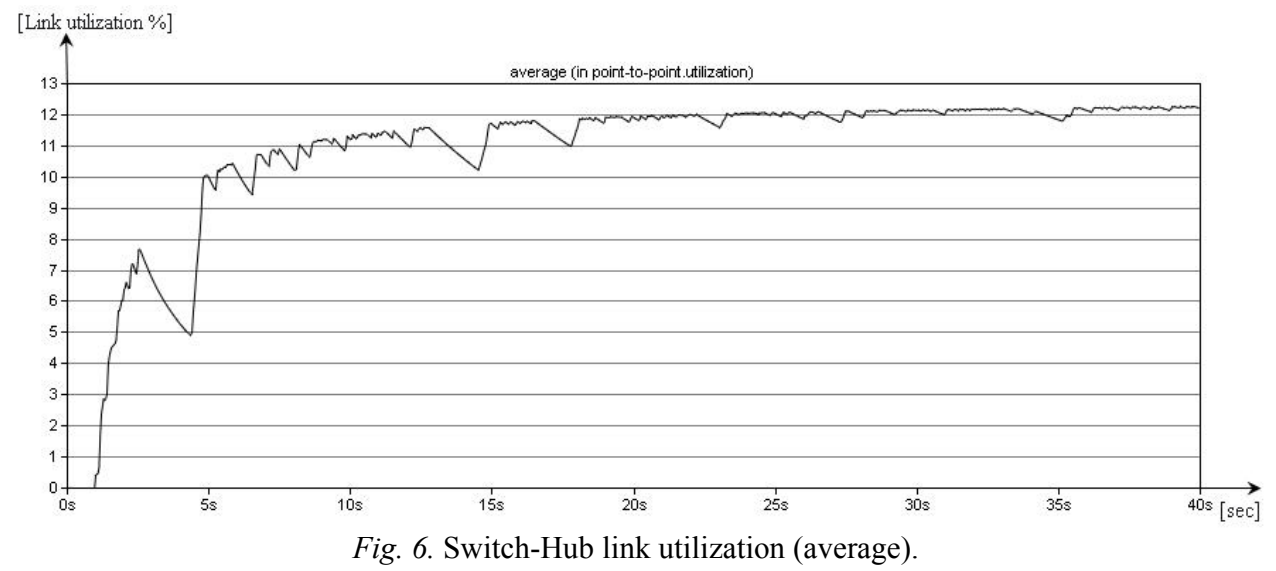






Fig. 7. Switch-Hub link utilization (real-time)

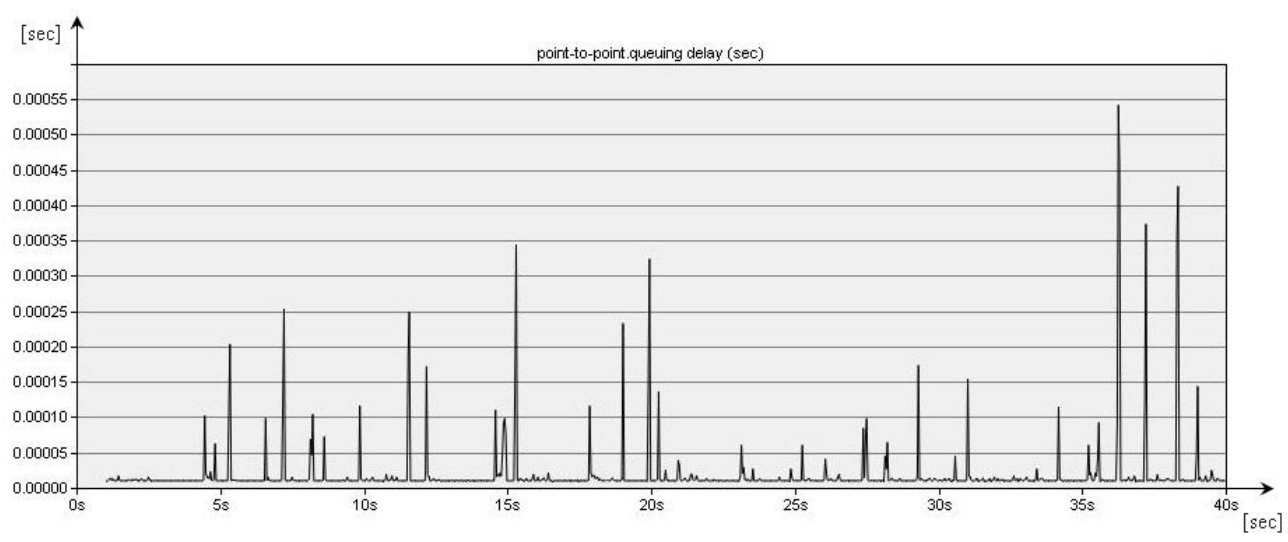

Fig. 8. End-to-end queuing delay (real-time)

The eye pattern is a powerful yet simple time-domain tool for assessing the data capability of an optical digital transmission system. The eye pattern measurements are made in the time domain and in real time showing the effects of waveform distortions immediately on the oscilloscope. Much system performance information can be deduced from the eye-pattern display. Information regarding the signal amplitude distortion, timing jitter and system rise time can be derived simply by observing certain features of the pattern. The eye-pattern obtained during simulations is analyzed to derive and compare various system performance characteristics [10].

The triple-play service is realized as a combination of data, voice, and video signals. To optimize the bandwidth in a PON, the transmission through the optical fiber path employs a coarse WDM (CWDM) technique with data and voice components transmitted at wavelengths in the range of 1480-1500 nm, and a video component within the 1550-1560 nm range. The high-speed Internet component is represented by different data links, with 1.25 to $10 \mathrm{Gbit} / \mathrm{s}$ downstream bandwidths. The voice component can be represented as VOIP service (voice over IP, packetswitched protocol), which is gaining popularity as an alternative to traditional PSTN (public switched telephone network) with POTS (plain old telephone service) at the customer end. The video component is represented as a 16-QAM subcarrier multiplexed (SCM) system. 

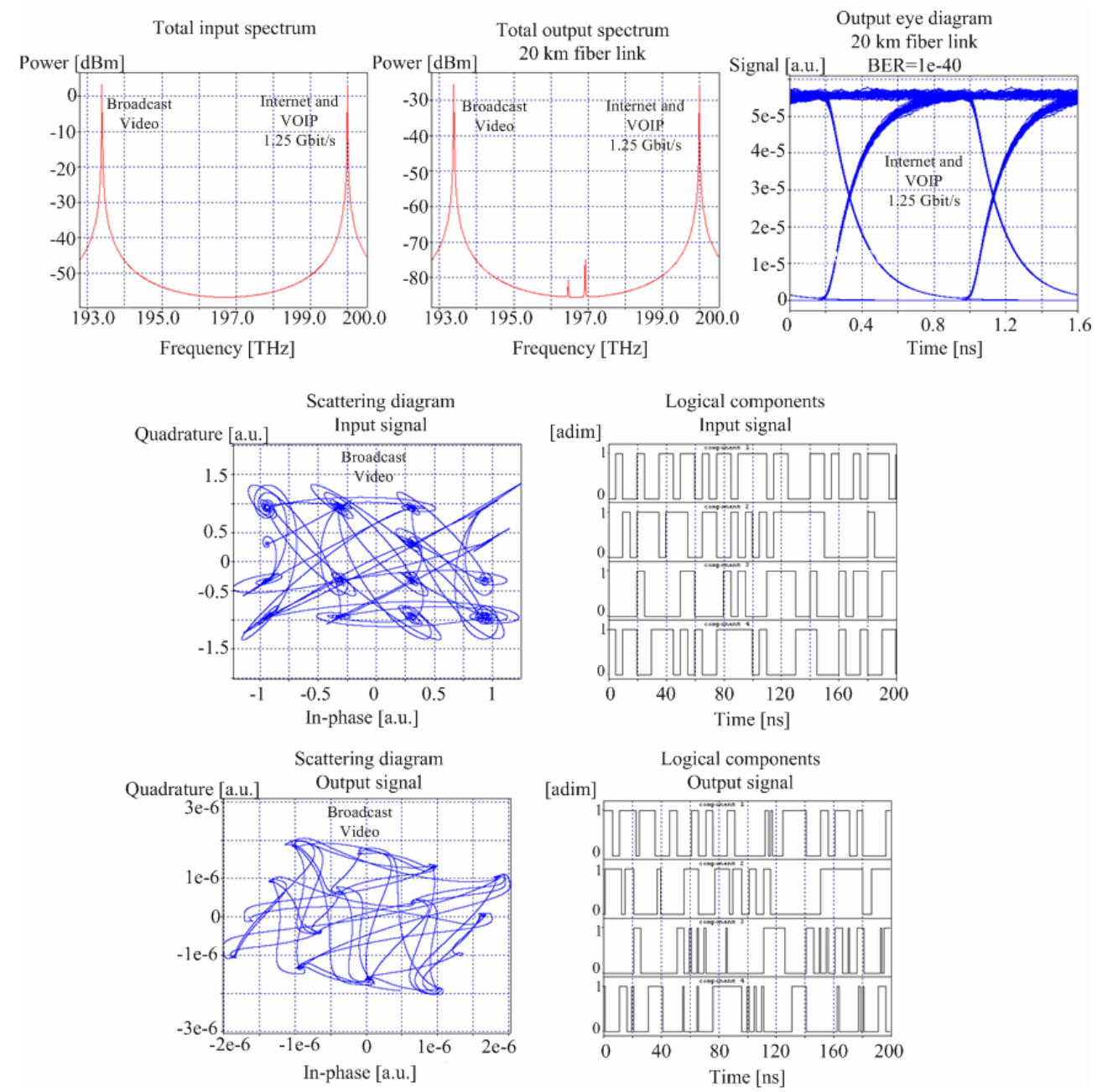

Fig. 9. Input and output spectra at the exit of a $20 \mathrm{~km}$ fiber.

The eye diagram obtained for $1.25 \mathrm{Gbit} / \mathrm{s}$ data signal.

Signal constellation and 4-level logical signal at 16-QAM encoder.

The signal from the central office travels through a $20 \mathrm{~km}$ long fiber distribution network and arrives at the optical network termination unit. The optical spectrum at the input to ONT is shown on Fig. 9. Here the optical signal is first demultiplexed into the data/voice and video components. The data component goes to the optical receiver. The optical power meters placed after transmitters and before receivers show that the total attenuation from the fiber spans and splitters is about $29 \mathrm{~dB}$, and that the input power to the receiver is about $-25 \mathrm{dBm}$. The receiver eye diagram for the data signal is given in the same figure. The choice of arbitrary units that are used on the Y-axis in the eye diagrams was purposeful - to make them more general in the cases when the plotted electrical quantity is current or voltage. The video component of the receiver signal enters the 16-QAM decoder. The lower part of Fig. 9 demonstrates a 4-level logical signal and a signal constellation plot for the 16-QAM encoder. When comparing the output eye diagrams it could be seen that the channel spacing is enough for excellent system 
performance (standardized by the ITU-T organization). The BER value of the data signal seen in the figure is more than sufficient [11].
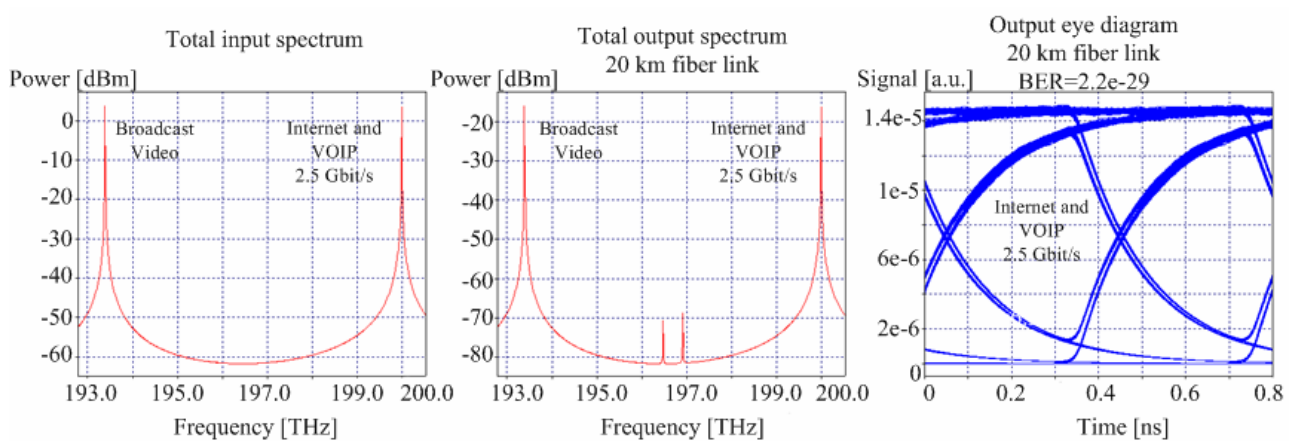

Fig. 10. Input and output spectra at the exit of a $20 \mathrm{~km}$ fiber.

The eye diagram obtained for $2.5 \mathrm{Gbit} / \mathrm{s}$ data signal.

The next simulations were performed to determine the existing PON FTTH systems' possibilities for upgrading. In that case it is necessary to set the power budget with various fiber links, and to estimate the characteristics of eye diagrams for the outputs with different bit rates.

Figure 10 presents the eye diagram of a transmitted $2.5 \mathrm{Gbit} / \mathrm{s}$ data signal and input/output optical signal spectra with the same system characteristics. Here the bit rate is two times greater than in the previous example, and the system performance remains sufficient. With the transmission speed increasing to $5 \mathrm{Gbit} / \mathrm{s}$ in the system a lower BER is achieved, so its performance degrades (see Fig. 11).
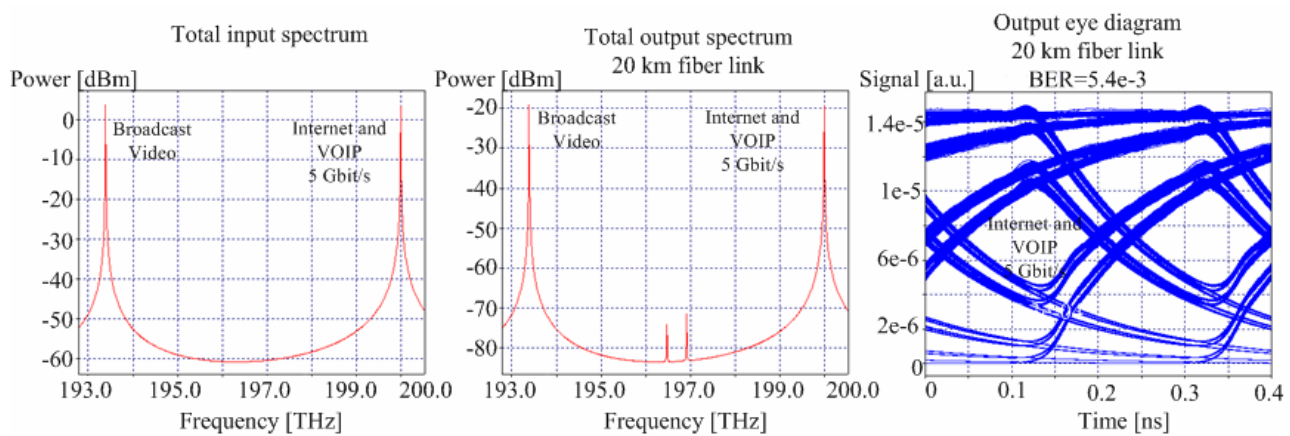

Fig. 11. Input and output spectra at the exit of a $20 \mathrm{~km}$ fiber.

The eye diagram obtained for $5.0 \mathrm{Gbit} / \mathrm{s}$ data signal.

These examples show that an optimal transmission speed (which will guarantee a sufficient BER) would lie somewhere between $1 \mathrm{Gbit} / \mathrm{s}$ and $5.0 \mathrm{Gbit} / \mathrm{s}$ with a standard PON architecture. It is possible to increase the bit error rate up to $10 \mathrm{Gbit} / \mathrm{s}$, but in that case we need to change the parameters of end-user equipment, particularly the electric filter's bandwidth (Fig. 12).

The main problem with $10 \mathrm{Gbit} / \mathrm{s}$ PONs, at the present time, is their high cost for end users; since we cannot replace the electric filter separately, we should replace the main transceiver unit with a photo-detector, which would be a factor limiting the PON development. It is envisaged that, in the nearest future, the PON- 
based access will be dominant. Primarily, this technology maturing fast, it allows the total cost to be shared among a larger number of customers. It is predicted that as a number of available HDTV channels grows even more bandwidths will be required. This could provide an incentive to quicken the development of $10 \mathrm{Gbit} / \mathrm{s}$ PONs based on FTTH modes and to significantly reduce the time of advance to market. Despite being in the laboratory phase, this technology might become available on the market in the next couple of years.
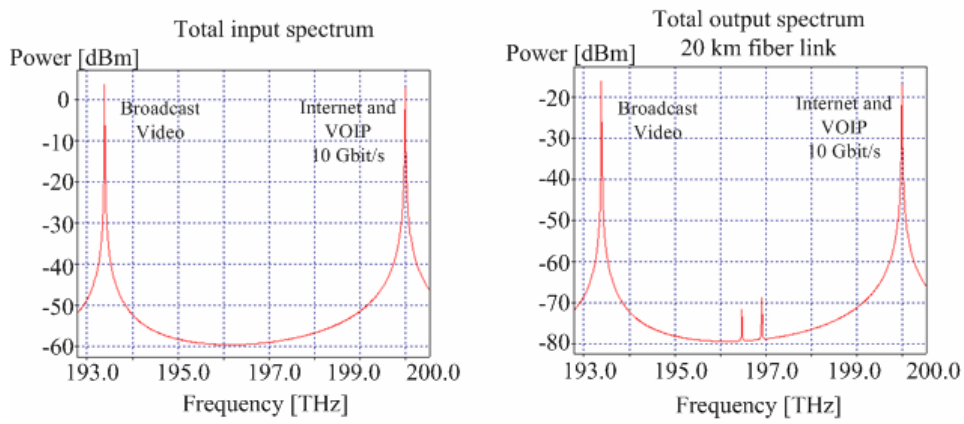

Different eye patterns with various electrical filtering on $10 \mathrm{Gbit} / \mathrm{s}$ signal output
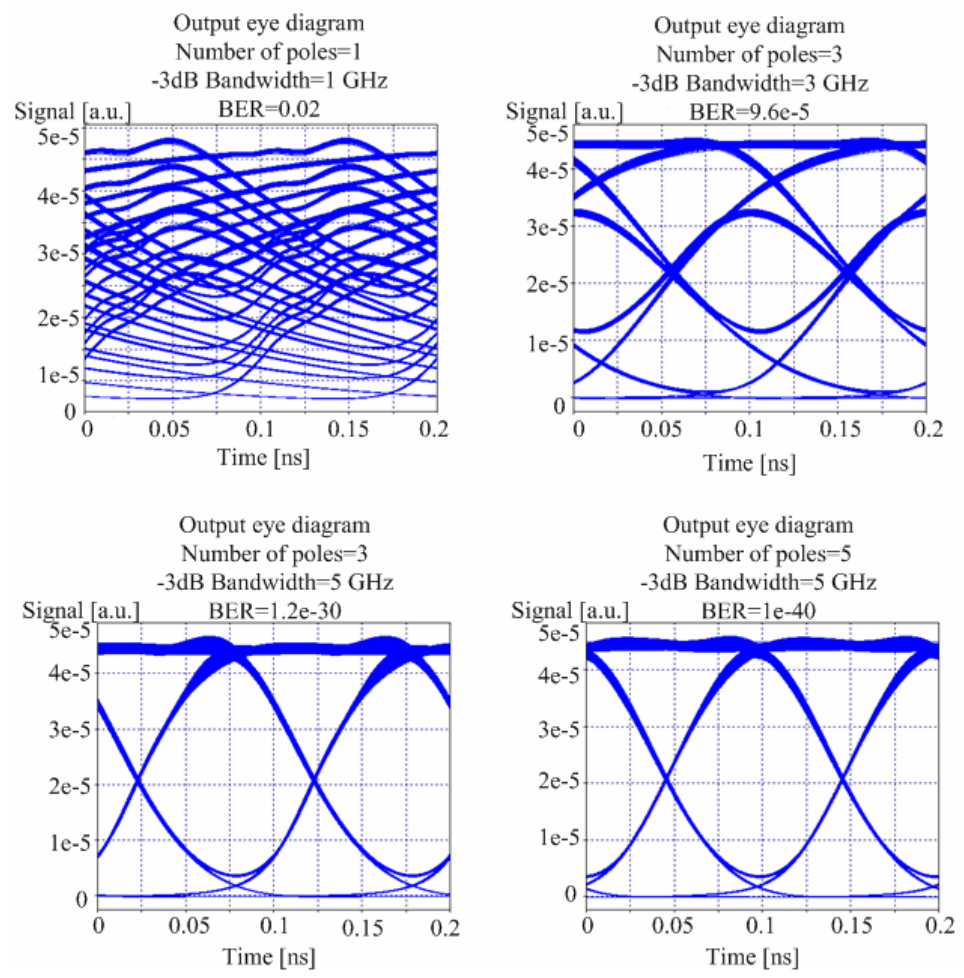

Fig. 12. Input and output spectra at the exit of a $20 \mathrm{~km}$ fiber.

The eye diagram obtained for $10 \mathrm{Gbit} / \mathrm{s}$ data signals with different electrical filtering.

In the standards specifying PON's functionality two distances: 10 and $20 \mathrm{~km}$ are considered. In our simulation, after replacement of the receiver's electrical filter, a $10 \mathrm{Gbit} / \mathrm{s}$ successful transmission is possible over $40 \mathrm{~km}$ (Fig. 13). 



Fig. 13. Input and output spectra at the exit of a $40 \mathrm{~km}$ fiber. The eye diagram obtained for $10 \mathrm{Gbit} / \mathrm{s}$ data signal.

\section{CONCLUSIONS}

Amalgamation of companies, working groups and industry regulatory bodies including the International Telecommunications Union (ITU) and the Institute of Electrical and Electronics Engineers (IEEE), are already considering the details of the coming $10 \mathrm{Gbit} / \mathrm{s}$ PON standard, provisionally called $10 \mathrm{G} \mathrm{PON}$ or $10 \mathrm{G}$ "Next Gen". The steps discussed in this paper are given as examples, and more or less steps may be needed in actual situations. In addition to the evolution scenarios and the corresponding system architectures, issues like the use of tunable lasers at ONTs, AWG wavelength tracking, and protocols for DWDM link need further study.

The main conclusions of our simulation are therefore as follows.

- An optimal transmission speed (which will guarantee a sufficient BER) for PON FTTH would lie in the range 1.25-5.0 Gbit/s with a standard architecture.

- It is possible to increase the bit rate of standard $2.5 \mathrm{Gbit} / \mathrm{s}$ PON FTTH up to $10 \mathrm{Gbit} / \mathrm{s}$, but in that case we need to replace the end-user equipment, particularly electrical filters.

- According to our simulation, after upgrading the receiver's electrical filter a $10 \mathrm{Gbit} / \mathrm{s}$ successful transmission will be possible over $40 \mathrm{~km}$ (in the standards specifying PON's functionality distances of only 10 and $20 \mathrm{~km}$ are considered).

- Since the downstream information is broadcast to all ONTs, these can receive all payloads of PON; therefore the privacy and security become serious 
issues. Also, the network diagnostics and fault identification of an outside plant in PON are very difficult. The current TDM-PON upgrading will therefore be a challenge, as its MAC protocol is highly complicated.

- In the current scenario for TDM-PONs, if more users are to be added, an entirely new PON with the capability of serving up to 32 users has to be deployed on the field, and a new set of transceivers at the OLT side is added inside the central office to serve a few additional users. Also, the available bandwidth of a single fiber when using TDM-PON is mostly wasted; moreover, the tree topology of current TDM-PON lacks the features of protection and restoration.

- TDM-PON is an effective and relatively cheap solution, however it implies over-provisioning and complicated cabling, so it may not be economically justified, and therefore more flexible designs are required to solve these problems.

\section{REFERENCES}

1. Hutchenson, L. (2008). FTTx: Current Status and the Future. IEEE Communication Magazine, 46, 90-95.

2. Hai, B., \& Geng, S. (2005). A GMPLS and EPON-based optical access network with end-to-end QoS guarantee for broadband IP services. Network architectures, management, and applications. Conf. No2, Beijing (CHINA), pp. 207-214.

3. Sierra, A., \& Kartalopoulos, S. (2006). Evaluation of Two Prevalent EPON Networks Using Simulation Methods. International Conference on Internet and Web Applications and Services, Le Morne, Mauritius. pp. 48-50.

4. Vukovic, A., Savoie, M., Hua, H., \& Maamoun, K. (2007). Performance characterization of PON technologies. Proceedings of the SPIE, 4, 67-96.

5. New FTTH Global Ranking (2008). Fiber-to-the-Home Council.

6. FTTH Worldwide Technology Update \& Market Forecast (2008). Heavy Reading. 61.

7. Leibrich, J., \& Rosenkranz, W. (2002). Efficient numerical simulation of multichannel WDM transmission systems limited by XPM. IEEE Photon. Techno. Letters. 5, 28-36.

8. Keiser, G. (2004). Optical Fiber Communications. New York etc.: Mc. Graw-Hill.

9. OptSim 5.0 User Guide.

10. Renxiang, H. (2001). Simulation and Experimental Study of WDM Optical Systems. Technical report. 1, 28-44.

11. Bobrovs, V., \& Ivanovs, G. (2006). Parameter evaluation of a dense optical network. Lithuanian Journal of Electronics and Electrical Engineering, 5, 33-37.

12. Stevens, H. \& Pettey, C. (2008). Gartner Says Cloud Computing Will Be as Influential as E-business. STAMFORD, Conn., June 26. Gartner press release.

\section{TRAFIKA VADĪBAS IZPĒTE DLX OPTISKAJĀ SAKARU SISTĒMĀ}

V. Bobrovs, J. Jelinskis, G. Ivanovs, G. Lauks

Kopsavilkums

Darbā, ar OPTSIM simulācijas programmatūras palīdzību pētìtas un salīdzinātas vairākas pasīvas optisku tīklu (POT) arhitektūras. Novērtēti tehnoloğiskie risinājumi dzīslā līdz x (DLx) fiziskajam slānim. Trafika simulācijas ir veiktas ar 
OPNET Modeler programmatūru un ir izveidotas rekomendācijas DLx sistēmas realizācijai. Autoru pētījums ir pamatots ar nepieciešamību integrēt jaunas sistēmas jau esošajos POT risinājumos. Pētījumā uzskatāmi demonstrēts kā optimālais pārraides ātrums POT DLx sistēmās atrodas starp 1,25 Gbit/s un $5 \mathrm{Gbit} / \mathrm{s}$ standartiem POT risinājumā. Mainot klienta gala aparatūru, iespējams paaugstināt ātrumu līdz $10 \mathrm{Gbit} / \mathrm{s}$ un palielināt attālumu no 20 līdz $40 \mathrm{~km}$, nemainot visu POT arhitektūru, bet mainot tikai uztvērēja bloka elektrisko filtru.

01.03. 2009. 